\title{
"EU NÃO ESTOU SÓ(MENTE) EM MEU CORPO" A PESSOA E O CORPO ENTRE OS TOBA (QOM) DO CHACO ARGENTINO*
}

Florencia Tola

\begin{abstract}
Um dia, quando eu visitava Gerônima, uma jovem mãe toba com uma filha de nove meses, ela não tardou a dividir comigo sua preocupação. Sua mãe estava zangada porque ela havia começado a menstruar, ainda que jurasse não haver retomado as relações sexuais depois do parto. A mãe, contudo, não acreditava nisso e desaprovava a falta de cuidado com o bebê. Gerônima - demasiado preocupada - pensara então estar doente e decidira consultar um médico. Para sua surpresa, o médico declarara que ela não sofria de doença alguma e que sua menstruação era um fato natural e independente das relações sexuais. Esta resposta não fez senão perturbar ainda mais a jovem, que não conseguia conciliar a posição de sua mãe, portanto, dos mais velhos, e a naturalidade destes dois fenômenos - aparentemente independentes — com a certeza de que, por amor à sua filha, ela não havia transgredido a proibição sexual durante o aleitamento, transgressão esta que poderia ter levado sua filhinha à morte.
\end{abstract}

Neste artigo, buscarei evidenciar os atributos que definem o corpo e a pessoa entre os Toba do Chaco argentino. ${ }^{1}$ Os conceitos "pessoa corporizada" e "extensões corporais" me permitirão dar conta da maneira segundo a qual o que chamamos de corpo e pessoa são concebidos e vividos por gente que não tem uma noção restrita de pessoa e que, portanto, não limita a condição de pessoa à pessoa humana; para quem a pessoa não termina nos limites impostos pelo corpo e para quem este último não constitui uma fronteira entre os seres existentes.

O tema da pessoa e do corpo afirmou-se ao longo das últimas décadas como um dos objetos clássicos dos estudos consagrados às populações das terras baixas da América do Sul. O artigo fundador de Anthony Seeger, Roberto DaMatta e Eduardo Viveiros de Castro (1979) constitui o ponto de partida de uma série de pesquisas dedicadas à noção de pessoa e ao tra- 
tamento do corpo. Mais do que ser tratada - como propunham os autores precedentes - como categoria analítica e operadora de integração social, a noção de pessoa ou de corpo foi tematizada por diversos autores no interior de domínios particulares, como o ornamental, o estético, de um lado; a doença, o xamanismo, a morte, de outro. Em artigo recente, Aparecida Vilaça (2005), menos interessada nos processos de fabricação do corpo do que naqueles ligados à sua transformação, analisa um dos aspectos que ela considera centrais nas concepções ameríndias do corpo: o caráter instável e transformacional deste último (Vilaça 2005:446). Ela propõe que nas sociedades ameríndias o corpo não é dado no nascimento; ao contrário, é constantemente criado ao longo de toda a vida através de diversos processos de transformação social. As substâncias transmitidas durante a gestação seriam então menos significativas do que aquelas adquiridas por ocasião das trocas durante as práticas sociais.

Se a partir dos anos 1970 os conceitos de pessoa e de corpo mostraramse particularmente produtivos para o estudo das sociedades amazônicas, possuindo raros elos com a sociedade nacional, estes dois temas não encontraram a mesma ressonância na antropologia argentina devido à sua história e às abordagens teóricas que dominaram os estudos do Chaco. Em função da maneira de se levar em consideração as sociedades indígenas e da alternância de tendências políticas que sucessivamente dominaram o discurso acadêmico, constituiu-se uma antropologia argentina que teve em seus extremos a "exotização" dos índios - essencializados a partir do contato místico e mágico com o mundo - e a proletarização dos mesmos enquanto sujeitos inseridos na práxis histórica, dominados e "submetidos ao Capital".

Nos primórdios da antropologia argentina, os índios tornaram-se o objeto de estudo de uma corrente acusada mais tarde de ser essencialista (Gordillo 1996), composta por antropólogos que, pouco interessados nas relações de dominação, abordaram as populações chaqueñas a partir de uma interpretação algo ingênua da fenomenologia. Estes trabalhos fizeram parte da nebulosa de pesquisas que se inscrevem no que pode ser chamado de lato sensu de uma fenomenologia da religião. Esta foi marcada por textos de Otto e de Eliade, que manifestaram um vivo interesse pela compilação dos mitos e procuraram a "consciência mítica" (Bórmida 1969), antes que os narradores fossem influenciados pela sociedade nacional e que as "estruturas irracionais do sentido" (Bórmida 1976) fossem "desfiguradas" por conceitos científicos. Desde 1970, Marcelo Bórmida e sua escola (De los Rios 1976, 1978-79; Mashnshnek 1976; Idoyaga Molina 1976, 1978-79; Tomasini 1978-79; Califano 1973; Dasso 1988), procurando captar a essência cultural dos índios do Chaco, aplicaram-se em salvar a mitologia, entendida como o 
meio privilegiado de acessar a cultura. Tal abordagem, inscrita na herança boasiana, dissimulava uma idéia evolucionista implícita e uma imagem ilusória do índio mergulhado em um estado nostálgico de pureza natural. Este apanhado sistemático da mitologia e sua apresentação detalhada, acompanhada de muito poucas notas críticas ou analíticas, oferecem um corpo mitológico precioso. ${ }^{2}$

Ao seguir o curso da história política argentina e a história da antropologia, a imagem do índio portador de um conhecimento mítico e em comunicação religiosa permanente com o mundo foi substituída pela do índio subalterno, dominado e estigmatizado. A partir dos anos 80 surgiu uma corrente que, sob a influência da crítica marxista da sociedade, interessou-se pelo estudo das sociedades do Chaco, visando levar em conta os mecanismos de dominação, os processos político-econômicos de expansão do capital e o processo de proletarização dos índios. Depois do desaparecimento dos "índios puros", os índios apareceram como representantes de um subproletariado. Na seqüência do restabelecimento do sistema democrático em 1983, antropólogos e historiadores (Iñigo Carrera 1979, 1983; Trinchero, Picinino e Gordillo 1992; Trinchero 1994; Trinchero e Leguizamón 1995, 1996) abordaram os processos históricos que fizeram dos índios chaqueños proletários marginalizados. Estes autores deram a seus textos a dimensão política da colonização do Chaco e mostraram que esta última era a causa da situação atual dos índios. Para eles, o processo de expansão do capital no Chaco, que teve por corolário a sedentarização progressiva dos índios e sua inserção no mercado regional, é a chave que permite compreender as transformações ocorridas na organização social das sociedades da região.

Este breve panorama da antropologia chaqueña permite observar os fundamentos teóricos que definiram uma antropologia dos índios do Chaco. Um fato significativo da história da etnografia desta região é que os estudos sobre populações indígenas foram construídos independentemente das problemáticas abordadas em outras sociedades indígenas das terras baixas e altas sul-americanas. Este hiato entre a antropologia do Chaco e a do continente em seu conjunto deu espaço a uma etnografia chaqueña constituída enquanto corrente à parte, cujas abordagens teóricas e metodologias são extremamente particulares.

Ao longo dos quatro séculos de contato com europeus, missionários e militares, os Qom - assim como as outras sociedades do Chaco - configuraram-se como mão-de-obra barata na indústria, possibilitando o desenvolvimento da região e afirmando-se como crentes evangélicos, anglicanos ou mórmons. Ao lado dos processos históricos que transformaram os índios em proletários marginais, aculturados, submissos e evangélicos - nas co- 
munidades toba, sedentárias e agrícolas, e nos bairros periféricos e urbanos da Província de Formosa e do Chaco - a reflexão sobre a pessoa e a constituição social do corpo impôs-se como linguagem central da sociologia toba. Neste artigo, mostrarei que mesmo nas sociedades inseridas em relações de subordinação no que diz respeito à sociedade nacional e em processos de marginalização permanente, os conceitos de pessoa e de corpo são suscetíveis de se constituírem em instrumentos centrais, tendo incidências sobre a maneira com que os indivíduos concebem e vivem os laços intersubjetivos. Mais particularmente, mostrarei que, para os Toba, os regimes de corporalidade são o resultado do agenciamentos das pessoas, agenciamentos estes tornados possíveis pela existência de extensões corporais e da pessoa.

\section{Extensões da pessoa corporizada}

Os Qom concebem a pessoa como extensa, na medida em que seu corpo não representa uma fronteira entre os seres existentes nem tampouco uma barreira que encerraria os elementos que a constituem. A pele é antes pensada como porosa, permeável e aberta, de modo que é difícil imaginar a existência de um interior e de um exterior corporal. O termo l'oc é geralmente traduzido por "corpo". Contudo, ele define mais precisamente o limite corporal marcado pela pele, no caso das pessoas; pelo couro, no dos animais; pela casca, no caso das árvores; e pela pele, no das frutas. Se l'oc é utilizado para traduzir isto que se chama "corpo", ele não inclui, entretanto, a totalidade do corpo: não inclui a carne (lapat), nem os fluidos ou os órgãos.

Para abordar o conceito toba de pessoa, analisarei inicialmente os componentes que constituem cada pessoa corporizada, assim como alguns processos que intervêm na formação e na transformação do corpo. O conceito de pessoa corporizada permite levar em consideração as estreitas relações entre a pessoa e os processos coletivos de constituição corporal. Por meio deste conceito, faço referência à pessoa humana, uma vez que ela se corporifica ou se "torna corpo" a partir das ações e das intenções de outrem. Este conceito permite ultrapassar a noção de corpo enquanto produto ou questão social, colocando em evidência o agente desencadeador humano associado ao processo de metamorfose corporal, o qual se mantém ao longo da existência corporizada de uma pessoa. Noutras palavras, a pessoa corporizada assim se torna graças a outras pessoas, que desencadeiam o advento e a sua transformação em um corpo.

Alguns componentes da pessoa são concebidos como suas extensões pelo fato de que, mesmo fora do limite corporal, contêm uma parte que 
pertence a ela ou, melhor, são a pessoa. No entanto, mesmo que todas as extensões tratem da condição extensa da pessoa, elas não constituem um bloco homogêneo. Mostraremos que determinados fluidos corporais (como o sangue e o esperma) são extensões pelo fato de provirem de outros corpos. Neste sentido, são extensões de outrem em nosso corpo ou são nossas extensões manifestadas no corpo de pessoas ligadas a nós por relações de parentesco e elos afetivos. Existe outro tipo de extensões feitas de componentes destacáveis da pessoa (como o lqui'i e o nome). Como alguns fluidos corporais, estes componentes podem vir de outras pessoas e, da mesma maneira que certos prolongamentos do corpo (como o calor corporal e o cheiro), eles são suscetíveis de serem capturados por inimigos e podem ter repercussões sobre a própria vontade, a intencionalidade, as emoções e os pensamentos. A ação exercida sobre estas extensões coloca em evidência a impossibilidade de dissociar a pessoa e o corpo - mais especificamente, a "personificação" do corpo e a "corporização" da pessoa.

\section{O Iqui'i}

Examinemos antes de mais nada a significação do componente da pessoa relatado pela maior parte dos Qom: o lqui'i. Ainda que inúmeros especialistas da região o tenham descrito entre os componentes do corpo, para a maioria deles o lqui'i é a alma que anima o corpo. Não colocando em questão a oposição alma / corpo, tais autores consideram este último como a sede da alma. Entretanto, projetar sobre os conceitos toba o sentido desta oposição própria ao Ocidente só contribui para obscurecer a maneira pela qual os Qom concebem, eles mesmos, a pessoa corporizada. Os termos que fazem alusão, em espanhol, ao lqui'i (alma, espíritu) tampouco permitem captar o modo pelo qual os Toba concebem o corpo e a pessoa. Na verdade, esta não é constituída de um corpo fixo e individual e de um espírito que a anima. $\mathrm{O}$ que faz com que um ente se torne uma pessoa humana é - conforme mostraremos - o fato de ser ele um lqui'i corporizado. Ainda que o lqui'i seja geralmente traduzido por alma, que a maioria dos especialistas do Chaco o associe a ela e que ele possua algumas características atribuídas à alma, o lqui'i está na origem de certas aptidões que o impedem de ser reduzido a esta noção.

Segundo a perspectiva toba, a pessoa existe de maneira potencial e virtual. Ela vive no céu enquanto lqui'i, antes de descer ao ventre feminino e começar sua transformação em corpo humano pela mudança sucessiva de fluidos sexuais, paternos e maternos, em órgãos. A pessoa não é, por- 
tanto, o resultado de um princípio exterior que se introduz em um corpo dado, concebido como natural, mas sim um lqui'i mesmo antes de nascer e adquirir aparência visivelmente humana. Quando as crianças potenciais do céu (lqui'i o'o) são depositadas no ventre de uma mulher que está grávida, em seguida a relações sexuais reiteradas, elas se tornam um corpo. O lqui'i é visto como um ente sem corpo; e até mesmo como uma pessoa potencial. Esta concepção de pessoa potencial demonstra que a ausência do corpo não é uma limitação para pensar a existência humana: as pessoas-bebê são dotadas da capacidade de experimentar emoções e de pensar, já que elas se beneficiam de uma vida no céu antes de se tornarem um corpo.

Seferino, um jovem xamã, reconstrói sua vida no céu a partir de seus conhecimentos sobre a vida dos lqui'i o'o. A seguir, uma parte de seu relato, que indica não apenas a influência cristã ${ }^{3}$ como também a de textos educativos:

Assim que eu vim ao mundo, colocaram-me em uma cápsula. Eu devia ficar nesta cápsula porque, se eu caísse, minha mãe abortaria. A cápsula era o corpo que estava se formando. Com esta cápsula o corpo se forma, ele é cozinhado, lhe é dada uma forma durante o período de um ano. Em seguida, chega um senhor vestido de branco que segura um bastão e toca a cápsula com o bastão. Eu fico com medo e adormeço. Assim que eu venho ao mundo, vejo dois cavalos voadores que chegam à Terra. Quando estão quase chegando, fazem uma espécie de salto e se voltam para outra direção. E eu caio [...] e eu grito [...] tenho medo. Caí dentro do mundo e aqui fui formado pela primeira vez. Caí no ventre de minha mãe e pensava que era o mundo. Quando eu bati, era mole: "estou afundando", eu me dizia. Depois, senti que havia um tubo em minha boca, senti antes algo que chegava e me permitia respirar. Eu ainda não tinha corpo, eu era sangue puro. Depois, eu sentia já a cabeça e o coração. A cabeça me dizia: "eu tenho um corpo".

Seferino estabelece uma distinção clara entre uma existência no céu, sem corpo, e a chegada à Terra, no ventre feminino. Neste momento, seu lqui'i tomou forma e adotou o corpo humano tão desejado durante sua existência no céu. Durante a gestação, os pais "formam e transformam" o corpo da criança, a partir de seus fluidos respectivos e da modificação destes em partes corporais do embrião. Antes de tudo, o cordão umbilical e a capacidade de respirar, em seguida, a existência do sangue e, enfim, a capacidade cognitiva permite pensar a existência de um corpo e de um coração que bate.

Entretanto, mesmo que o lqui'i se torne um corpo, dando vida à pessoa corporizada, ao se distanciar do corpo, ele não causa a sua morte. Na verdade, o lqui'i pode deixar o corpo ou afastar-se dele temporariamente em certas 
circunstâncias, sem com isto provocar a morte da pessoa. A esse respeito, padre Ducci menciona que os Toba "crêem na existência da alma humana, que eles chamam nquihi. Consideram que ela vaga constantemente" (1904:12). O antropólogo argentino Pablo Wright precisa, por sua vez, que "o lqui'i é uma espécie de imagem-alma que deixa o corpo durante os sonhos ou depois da morte" (1997:229). O lqui'i dos adultos deixa habitualmente o corpo durante os sonhos para visitar outras pessoas, vivas ou mortas. É por isto que muitos Qom esperam alguns minutos antes de saírem da cama, ao despertar, para dar ao lqui'i tempo de encontrar seus corpos e evitar, assim, que ele fique um longo período em deslocamento ou - como se diz hoje em tom de galhofa - enrolado no mosquiteiro.

Se a existência dos lqui'i de crianças potenciais consideradas pessoas mostra que o lqui'i não pode ser reduzido à idéia de alma, outro elemento contribui para que não se considerem como iguais estas duas noções: todos os entes possuem um lqui'i. Esta não é, com efeito, uma propriedade exclusiva dos seres humanos: todos os animais, seus espíritos-mestres e as outras "raças de pessoas" (os habitantes não-humanos da floresta, das águas etc.) possuem um lqui'i que lhes dá vida, permitindo também o movimento de seus corpos e conferindo-lhes sua própria imagem. ${ }^{4}$ O lqui'i permite tanto aos humanos quanto aos não-humanos (espíritos xamânicos, mortos, mestres das espécies etc.) a capacidade reflexiva, a intencionalidade, a comunicação, assim como a percepção visual. É por isto que, quando o lqui'i se distancia temporariamente do corpo, a pessoa perde uma parte ou a totalidade de sua consciência. Diante de meu interesse pelas características do lqui'i, um homem idoso de Mala' empreende uma síntese de suas múltiplas atitudes: "quando a criança está no ventre da mãe, ela já tem seu lqui'i e é por isto que ela mexe. Quando ela nasce, o lqui'i permite ver tudo, respirar, mexer, compreender, ouvir, pensar, escutar e conhecer".

Citemos outro fato que nos impede de assimilar completamente o lqui'i à noção de alma: sua ausência prolongada do corpo não implica a morte da pessoa. As ausências voluntárias do lqui'i e sua captura por outra pessoa são uma das causas das doenças e dos sofrimentos amorosos que devem ser curados pelos xamãs. Os feiticeiros podem capturar os lqui'i que vagam longe do corpo durante os sonhos e manipular as emoções-pensamentos (icuennataxa) das pessoas cujo lqui'i está ausente. Em função de o lqui'i permitir experimentar emoções e ter pensamentos, quando ele está sob posse de outrem, a pessoa perde o controle de si. Os xamãs são encarregados de encontrar a totalidade ou parte do lqui'i que escapou ou foi capturado e de fazê-lo retornar ao corpo da pessoa enfraquecida pela doença ou pelo amor não correspondido. Em geral, o lqui'i se distancia do corpo, mas retorna 
rapidamente e produz apenas um enfraquecimento temporário. É o caso do lqui'i das crianças, que é particularmente suscetível de se afastar do corpo, devido ao fato de ainda não estar estabilizado de maneira definitiva. Esta é a razão pela qual pode vagar mais facilmente do que o lqui'i de um adulto, e permanecer na floresta distraído por uma pessoa não-humana.

Mesmo que atualmente a idéia de uma participação divina na atribuição do componente que possibilita vitalidade ao bebê em gestação esteja muito disseminada devido à influência evangélica desde os anos 40, ela não está em contradição com esta outra, segundo a qual pai e mãe são encarregados, durante a gestação, de dar à criança seu lqui'i, entendido como aparência física. $O$ feto não se forma somente a partir da união e da transformação dos fluidos sexuais no ventre feminino, mas recebe, ao longo dos quatro primeiros meses, seu lqui'i e mesmo sua imagem corporal. Se para a versão dominante na atualidade Deus confere espírito à pessoa, outras versões afirmam que, para além de Deus, pai e mãe são encarregados de transmitir o lqui'i à criança em gestação.

\section{Os fluidos oferecidos in utero}

A gestação é concebida pelos Qom como um longo processo que exige subsídios constantes de outras entidades além da mãe - humanas e nãohumanas; masculinas e femininas. Assim como várias sociedades das terras baixas sul-americanas e de outros continentes, os Qom consideram que um ato sexual único não é suficiente para gerar uma criança. ${ }^{5}$ A expressão comum "é preciso trabalhar muito para fazer uma criança" dá conta da importância atribuída à constância do ato sexual pensado como uma atividade em conjunto. ${ }^{6}$ Por meio de freqüentes relações sexuais, o casal começa a dar forma à criança, a partir de sucessivos depósitos seminais no ventre da mulher. As relações sexuais constantes durante um período relativamente variável conduzem a uma nova gravidez.

A preponderância de um princípio gerador masculino na procriação, confrontando-se com outro, passivo e feminino, é um dos fatores que várias sociedades procuraram justificar (Héritier 1994, 1996). Dois tipos de respostas impõem-se a esta questão do papel dos fluidos masculinos e femininos: seja um só princípio ativo (masculino ou feminino) necessário à criação de um novo ser, sejam os princípios ativos masculinos e femininos intervindo em conjunto como agentes desse processo. De acordo com os Qom, o esperma (Imale) que se acumula no corpo feminino não é a única condição da procriação. A mulher deve ter em seu ventre um espírito de bebê (o'o lqui'i), que é a 
imagem da criança descida do céu. Se uma mulher deseja ter uma criança, depois de algum tempo tal imagem materializa-se dentro de seu corpo. Esta é a razão pela qual a maior parte das mulheres declara que o início de sua gravidez é um sonho no qual a criança vem do céu em direção ao ventre. O sonho - entendido como o meio pelo qual uma entidade não-humana dá o lqui'i da criança a uma mulher - contribui para tornar ainda mais complexa a idéia de uma concepção que não se funda exclusivamente na combinação dos fluidos corporais. Soma-se a isto a intervenção de um elemento não-humano tomado como um dos motores da concepção. Sem a presença em seu ventre de um espírito de bebê, uma mulher não poderia gerar uma criança, mesmo que ela tivesse relações sexuais com um homem.

De acordo com os Qom, ao longo dos quatro primeiros meses de gravidez, a criança forma-se e transforma-se a partir da união do esperma com o sangue menstrual e o sangue intra-uterino. Segundo uma jovem toba, "somos todos feitos de sangue e de lmale' [esperma]. Por isto, a criança conhece o odor do pai e da mãe quando ela nasce". O sangue menstrual que não escorreu, tendo sido a menstruação interrompida ao se dar a concepção, contribui para a formação da criança dentro do ventre da mãe. O sangue é o principal elemento do corpo, uma vez que suas composição e circulação determinam a boa saúde e o crescimento de cada pessoa. O sangue da menstruação, o esperma e o leite são concebidos como suas transformações ou seus derivados. Esses fluidos passam de um corpo a outro através de seus orifícios e da pele, de modo que, com o tempo e o decorrer das relações, a constituição do sangue própria de cada pessoa é diferente. Assim, entre aqueles que compartilham os fluidos corporais, desenvolve-se e circula o mesmo sangue, que concorre para a criação de um corpo comum e de uma memória dos pais. A explicação de duas irmãs toba torna explícita a associação entre o sangue, o sangue menstrual e o esperma:

Graciela: "A mulher fica menstruada a cada mês para evacuar o sangue produzido em seu corpo."

Olga: "Cada mês, o corpo produz mais sangue necessário à menstruação. Se lhe retiramos o útero, a mulher deixa de menstruar. Por isto, é necessário retirar-lhe o excesso de sangue. Uma mulher que a gente conhecia [de quem havia sido retirado o útero e que não menstruava mais] e de quem não havia sido retirado o sangue, tinha os dedos todos inchados pelo excesso de sangue."

F.T.: "Como faz o homem então [com o excesso de sangue]?"

Graciela: "E aquilo que ele retira?"

F.T.: "Como?"

Graciela: "O Imale [o esperma]!!" 
O esperma é composto de sangue e pelo fato deste último ser capaz de gerar a vida, o calor e a saúde, o esperma também possui o potencial de gerar vida. Um homem, tendo sangue forte, dispõe de um esperma forte, o que se manifesta na rapidez com que sua mulher engravida. O esperma pode ser fraco ou forte, porque está relacionado à alimentação e ao líquido ingerido. Se um homem alimenta-se de animais silvestres, seu sangue torna-se progressivamente mais forte em razão da transformação dos fluidos animais no sangue humano e da sua assimilação a ele. Dentre os alimentos da floresta, o peixe é um dos mais apreciados, pois ele tem incidência sobre a saúde, a força e a potência sexual. A associação metonímica entre o esperma e a medula do peixe, pela cor e pela consistência, é a fonte de uma série de expressões relativas a um aumento da quantidade de esperma devido à ingestão do peixe. Quando uma mulher diz a seu marido "você quer comer peixe? [Ainaxanaqte]?", ela deseja que ele tenha muito esperma pois, segundo Mirta, "o peixe tem bom líquido, que dá força para ter relações sexuais". É muito freqüente um pai dizer a seu filho "coma peixe para ter mais semente [semente = esperma: ainaxanaqte]".

Se no começo da gestação existe uma associação entre o esperma e o peixe, uma disjunção se estabelece entre esses fluidos em outros momentos do ciclo feminino. Se o esperma tem necessidade de peixe para se fortalecer e, assim, pode transformar a criança em gestação, a mulher menstruada recusa este alimento que poderia nela provocar uma forte hemorragia. O sangue da menstruação não deve ser unido nem ao esperma (daí as relações sexuais serem proibidas durante este período), nem a um alimento aparentado diretamente com o esperma e a fecundidade.

Existe igualmente uma difundida correlação entre o esperma e o sangue masculino trazido para a mulher durante as repetidas relações sexuais. Em cada ato sexual, o homem deixa uma parte de seu sangue na mulher. O esperma - este fluido que existe como tal fora do corpo da mulher torna-se sangue no seu corpo. Tal idéia sobre a relação deste último com o sangue feminino não era diretamente transmitida pelas mulheres, mas surgia constantemente durante conversas informais, e foi confirmada diversas vezes tanto pelos homens quanto pelas mulheres. Uma vez dentro do corpo da mulher, este fluido se faz sangue. Por outro lado, se o esperma traz à mulher uma parte do sangue masculino e se as primeiras relações sexuais depois do parto provocam a volta da menstruação na mulher, há uma vinculação estreita entre o esperma-sangue e o sangue menstrual. ${ }^{7}$ Por isto, no extrato que apresentei no início deste texto, mesmo quando a jovem mãe afirmava não ter retomado as relações sexuais depois do parto, sua mãe não acreditava no que ela dizia, uma vez que Gerônima já havia 
começado a menstruar. Com efeito, de acordo com a perspectiva toba, o homem produz a menstruação post-partum a partir da contribuição de seu esperma-sangue. O esperma acumula-se no ventre feminino até escorrer sob a forma de sangue menstrual.

Todavia, para além da associação entre sangue menstrual e esperma, diversas mulheres expressam a idéia de o útero conter sangue propriamente feminino, que escorre a cada mês. O fato de mulheres que ainda não têm relações sexuais apresentarem menstruação indica que o sangue menstrual não é, em todos os momentos do ciclo reprodutivo feminino, sangue gerado pelos homens. Cada mulher possui uma quantidade suplementar de sangue que escorre uma vez por mês com o esperma-sangue. "A menstruação é necessária porque, do contrário, o saco se enche de sangue. É preciso que ele saia para que a mulher possa carregar um bebê em sua barriga", explica Betty. Segundo a visão feminina, este sangue não pertence ao homem nem às suas contribuições de esperma; representa, antes, o sangue próprio à mulher, permitindo o processo de gestação a partir de sua mistura com o esperma.

De acordo com Vilaça (1992:52), os Wari consideram que o corpo da criança é criado pelo esperma e pelo sangue menstrual. Contudo, diante das questões relativas aos processos de gestação, a versão dominante era aquela que via apenas no esperma o fator de formação da criança. Se poucos falavam espontaneamente da participação do sangue menstrual, quando o etnólogo formulava questões sobre o papel deste fluido na gestação, mesmo aqueles que insistiam no papel ativo do esperma confirmavam a importância da associação do sangue menstrual. Parecia existir entre os Qom esta mesma idéia generalizada, explícita e dominante quanto ao esperma como formador da criança. Se aprofundarmos este tema com interlocutoras femininas, constataremos que o esperma não é — da mesma forma que crêem os Wari "o componente físico exclusivo do corpo da criança; ele é, sem qualquer dúvida, o elemento mais importante da teoria da gestação" (Vilaça 1992:52).

\section{O calor corporal e o nome}

A constituição e a transformação de cada pessoa corporizada não se limitam a transmitir fluidos corporais entre pessoas aparentadas. Elas dependem também da circulação de outros componentes e da incorporação de certas substâncias ao longo da vida. Estes componentes não são exclusivos dos seres humanos, não mais do que o é o lqui'i. Eu mostrarei que o calor corporal e determinados nomes são concebidos também como extensões da pessoa corporizada. 
O calor corporal (lapaxayaxa) é uma característica própria de todo ser vivo que possua um corpo, em oposição aos corpos de pessoas mortas. O calor é um atributo corporal sem o qual uma pessoa não seria totalmente humana. Sua ausência define a diferença entre um corpo vivo e outro morto, assim como entre os humanos e os não-humanos privados de corpo. O calor é um constituinte da pessoa que deriva do movimento do corpo e da circulação do sangue. Ele é igualmente associado à existência de um lqui'i corporizado: um lqui'i sozinho não tem mais calor do que um corpo sem lqui'i. Entre os seres humanos, pode acontecer que o calor corporal, difundido pelos objetos em contato direto com o corpo, seja desviado por agressores xamânicos ou apropriado por pessoas não-humanas. As conseqüências dessas ações e intenções sobre uma extensão do corpo são o enfraquecimento, a doença e a morte daquele que é privado do calor de seu corpo. É o caso das cadeiras e dos objetos pessoais que conservam o calor humano. Por isto, durante a noite, muitos desses objetos são localizados no interior das casas, a fim de protegêlos da influência de pessoas não-humanas ou de agressores xamânicos.

O nome (nlonaxat) ${ }^{8}$ conserva uma relação metonímica com a pessoa. A atribuição e a transmissão dos diferentes nomes explicitam um reconhecimento público e coletivo do elo social que une cada indivíduo ao seu grupo de parentes. De acordo com a lógica atual de transmissão de nomes, ${ }^{9}$ o nome de um parente não é transmitido a um membro da geração que se segue imediatamente (G-1), mas a um membro da geração posterior (G-2). Avós e netos têm às vezes um mesmo nome ou uma parte dele. Todavia, desejar não esquecer um genitor recentemente falecido não é razão suficiente para fazer uso de seu nome na geração seguinte, pois seu lqui'i — que continua a viver alhures - interpreta este ato como um chamado. Ele retorna então a Terra para "levar com ele" aquele que possui seu próprio nome. Este medo de se apropriar do nome de um genitor recentemente falecido foi assinalado, em 1932, por Karsten. O autor interpreta este traço segundo a idéia de que "a alma de uma pessoa é inerente ao seu nome" (1932:200). De acordo com tal interpretação, conhecer o nome de uma pessoa equivale a capturar uma parte de seus cabelos ou de suas unhas, no sentido de que isto implica possuir materialmente a alma do genitor falecido.

As teorias qom sobre certas restrições e o medo de perder partes ou prolongamentos do corpo não decorrem, entretanto, desta idéia relativa à "alma". O nome, certas partes do corpo e os elementos que estiveram em contato direto com ele são extensões da pessoa cuja unidade ultrapassa o corpo. Ela se espalha pelas partes constitutivas de seu corpo assim como pelos elementos constitutivos exteriores à própria pessoa. Esta associação do eu, do nome e do apelido explicita-se nas práticas de feitiçaria: um apelido escrito sobre um 
papel ou o nome escrito sobre a carteira de identidade são objetos dos quais uma feiticeira (qonaxanaxae) ${ }^{10}$ se serve para enfeitiçar a vítima.

Antigamente, o conjunto dos nomes inseria o indivíduo nas redes de parentesco, nas alianças e nos conflitos entre as "tribos" e nas relações em que a intersubjetividade destas últimas e dos "bandos"11 construíam a identidade de umas em relação às outras. Vários especialistas do Chaco ressaltam que cada tribo Toba tinha um nome (Braunstein e Miller 1999). Métraux (1963:302) já havia observado que o nome da tribo evocava animais, plantas e partes do corpo. Cada bando tinha também um nome ligado ao seu lugar de proveniência. Miller chama esses nomes de "termos regionais / direcionais" para indicar que eles "correspondem de maneira geral às sub-regiões ecológicas" (1979:27); eles estão ainda em vigor na maioria das comunidades do Chaco.

Cada pessoa possuía ainda um nome próprio, que fazia referência a uma característica física ou que era associado a um acontecimento de sua história pessoal. Enfim, além do nome pessoal dado pelos pais alguns meses após o nascimento, os Qom impunham um nome coletivo, o que indicava a importância do bando na constituição da pessoa. Os jovens solteiros recebiam este nome durante uma festa, ao longo da qual os adultos atribuíam um novo nome a cada um deles, que formavam uma fila e deviam passar no meio de dois grupos de adultos. Estes davam-lhes tapas nos ombros, repetindo um nome, escolhido por um homem idoso, que seria em seguida utilizado como primeiro nome. Hoje, os homens idosos conservam um nome toba além daquele de seu bando e de outro em espanhol, enquanto os jovens possuem apenas um nome em espanhol.

Na atualidade, a utilização de apelidos ( $n^{\prime}$ anaxat $)^{12}$ é muito difundida. Os jovens têm freqüentemente um apelido dado por sua família ou por seus companheiros. Este termo, como o antigo nome toba, indica talentos e atitudes da pessoa - suas marcas distintivas — e faz referência a uma característica física ou a um atributo de seu comportamento. À diferença dos nomes dados em homenagem a um ascendente ou por causa do pertencimento a um bando, os apelidos permitem identificar as pessoas segundo suas particularidades físicas ou suas qualidades, o que implica uma forma de conhecimento de outrem que não é fundada nas determinações sociais, mas nos traços individuais.

\section{Conclusão}

Ao longo deste artigo, analisei a maneira pela qual os Toba concebem a pessoa corporizada. Busquei mostrar que esta se constitui como extensa ou 
torna-se extensa graças ao seu corpo composto de extensões ou elementos destacáveis (os fluidos, o lqui'i, os nomes, o calor corporal etc.).

Bem no início, pela circulação dos fluidos e pela atribuição da imagem corporal durante a gestação, a pessoa corporizada é progressivamente formada e transformada por seus pais. As extensões corporais que circulam entre os homens, as mulheres e as crianças dão lugar aos regimes de corporalidade que a pessoa adota quando ela combina os componentes de outrem - regimes de corporalidade que são possíveis graças à condição extensa da pessoa.

As extensões corporais permitem que se dê conta do fato de que a pessoa não está só ou somente em seu corpo. Os regimes ou as manifestações de corporeidade são o registro e a condição das relações intersubjetivas que ocorrem entre pessoas cujos corpos tornam-se o espaço onde se dá o devir da pessoa, devir este que está sempre em função das ações e das intenções de outrem.

No entanto, como é possível a coexistência da idéia de indivíduo singular que, pelo seu corpo, diferencia-se dos outros indivíduos com a idéia de que aquilo que o constitui enquanto tal são as relações tecidas com outras pessoas múltiplas e extensas? O corpo é a sede da diferença entre os entes; ele estabelece a diferença entre as espécies e, no interior de algumas espécies, entre o masculino e o feminino. Entretanto, posto que o corpo advém de uma série de ações e se transforma por meio delas e que, menos do que ser concebido como entidade fixa, ele adota diversos regimes de corporeidade resultantes do agenciamento das extensões de outrem, o corpo é também a expressão da continuidade entre os entes. Esta continuidade permite pensar um conjunto formado de componentes e de influências de todos os entes; ela implica também a idéia de que o indivíduo é uma faceta possível ou uma consolidação particular de um conjunto relacional que, de acordo com as intensidades das relações, exprime-se adotando diferentes regimes de corporalidade, condensações circunstanciais de fluidos, atributos e capacidades. Note-se aqui um mecanismo de individuação que opera mesmo quando a pessoa é concebida como um feixe no qual se entrecruzam relações.

Contudo, se entre os Toba a pessoa é concebida como composta, o que então define sua individualidade? Ou, noutras palavras, como é concebido o indivíduo se a pessoa se revela múltipla em função de suas extensões corporais e da continuidade com outras pessoas? Uma resposta a esta questão remete-nos ao lqui'i. Ele existe como singularidade antes de se corporizar pela seqüência das intenções e das ações humanas e não-humanas, e também como singularidade quando uma pessoa morre e ele permanece de maneira individual enquanto espírito descorporizado. Mesmo que tenha 
havido ações visando advir a pessoa corporizada, ela existe como individualidade. Uma vez esta singularidade adote um corpo, a pessoa torna-se múltipla através dele.

As manifestações corporais da pessoa - as quais tornam possível o surgimento de outras pessoas - são concebíveis apenas por ser o corpo individual composto de relações e de outros seres humanos, já que os regimes corporais são a conseqüência das ações e das intenções de outrem, enfim, porque a individuação se liga à subjetivação do corpo e à objetivação da pessoa em suas extensões.

Uma outra resposta à questão relativa à individualidade de alguém remete-nos à expressão da agência. Ainda que as relações se estabeleçam a partir da corporificação da pessoa e que esta seja constituída de outras pessoas-corpo, ela não é um agente passivo de tais relações. Ela existe como indivíduo a partir do momento em que agencia ou não as extensões de outrem, ativando assim diversas reações nela e nos demais. Quando outras pessoas agem, produzem conseqüências sobre si mesmas em função da continuidade "anímica" e das conexões corporais. Por um lado, é nas ações exercidas sobre outrem que se exprime a capacidade pessoal de transformar o curso das relações substancialmente criadas. Se o processo de gestação depende das ações não-humanas, a aparência física da criança e sua saúde dependem das ações dos genitores. Por outro lado, nas ações exercidas pelas outras pessoas, exprime-se também a própria agência. Mesmo que sua saúde seja concebida como manifestação da intencionalidade de outrem e como registro da ativação das relações, as pessoas podem contornar as conseqüências dessas ações. Via ação xamânica, elas manifestam sua capacidade de agir, uma vez que os efeitos das ações de outrem são dominados e novos procedimentos intencionais desencadeiam-se.

Recebido em 15 de fevereiro de 2005

Aprovado em 05 de março de 2007

Tradução de Ana Carneiro Cerqueira

Florencia Tola é pesquisadora do Conseil National de la Recherche Scientifique et Technique (CONICET) e membro associado à Equipe de Recherche d'Ethnologie Amérindienne. E-mail: <tolatoba@yahoo.com.ar>. 


\section{Notas}

* Yo no estoy solo (sólo) en mi cuerpo. Esta frase é uma parte do título de minha tese de doutorado defendida na École des Hautes Études en Sciences Sociales, em 2004, sob a orientação de P. Descola e P. Wright. Gostaria de agradecer a Fondation Fyssen pela bolsa de pós-doutorado que me permitiu continuar as pesquisas sobre os Toba durante os anos 2004-2005.

${ }^{1}$ Este artigo baseia-se em pesquisas de campo efetuadas ao longo dos anos 1997-2003 em um período total de dois anos, em Mala' lapel e Namqom, duas das 16 comunidades toba do Chaco argentino. Os Toba ou Qom pertencem à família lingüística Guaycurú, que habita o Grande Chaco sul-americano. O Grande Chaco é constituído de uma ampla planície de acúmulo pluvial que se estende pelos territórios atuais da Argentina, da Bolívia e do Paraguai, por uma superfície de $600.000 \mathrm{~km}^{2}$. A oeste, o Chaco é delimitado por montanhas subandinas; a leste, pelos rios Paraguai e Paraná; ao norte, pelo planalto do Mato Grosso; e ao sul, pela bacia do rio Salado. A região é subdividida em três partes: o Chaco Boreal ao norte do rio Pilcomayo, o Chaco Central entre o Pilcomayo e o rio Bermejo e o Chaco Austral ao sul do Bermejo.

${ }^{2}$ Alguns mitos já haviam sido sistematizados por etnógrafos de origem européia, vindos ao Grande Chaco no início do século XX (Nordenskiöld 1912; Karsten 1926, 1932; Métraux 1937, 1946; Kersten 1968). Além das mitologias, estes últimos haviam descrito, em suas vastas monografias elementares, os temas clássicos da antropologia ligados ao conceito de pessoa e ao tratamento do corpo: as práticas do escalpo, as tatuagens e as escarificações, as danças rituais, as técnicas xamânicas etc.

${ }^{3}$ Desde 1940, proliferaram no Chaco argentino várias igrejas indígenas (a mais antiga é a Igreja Evangélica Unida) em torno de líderes indígenas carismáticos. El Evangelio é a maneira pela qual os Toba se referem ao movimento religioso evangélico que incorporou, desde o seu início, elementos do Cristianismo pentecostal e elementos do xamanismo toba.

${ }^{4} \mathrm{Na}$ verdade, o lqui'i imprime o caráter específico a cada corpo a partir da aparência corporal.

${ }^{5}$ Nas idéias sobre a procriação de uma grande parte dos grupos indígenas da América do Sul, encontra-se freqüentemente aquela em que a concepção é um processo gradual. Segundo Hugh Jones, entre os Tukano do Vaupés, a mulher só é considerada grávida a partir do momento em que ela é "preenchida por relações sexuais repetidas" (1979:115). De acordo com Viveiros de Castro, para os Araweté, a criança é formada por contribuições freqüentes de esperma (1992:129). Fazer uma criança é, para os Araweté, um longo trabalho que necessita de freqüentes copulações, a fim de que uma grande quantidade de esperma possa produzir o feto (Viveiros de Castro 1992:179). 
${ }^{6}$ Ver o conceito de "partible paternity" ou as "culturas de múltiplos pais" (Beckerman e Valentine 2002).

${ }^{7}$ Várias sociedades estabeleceram esta associação entre o esperma e o sangue menstrual. Quanto a isto, Héritier assinala que "depois de Aristóteles, os autores médicos nunca deixaram de destacar que as mulheres casadas têm menstruação mais abundante do que as moças, o que eles explicavam pelo aporte da substância espermática" (1994:90).

${ }^{8} \mathrm{~N}$-lon-axat: substantivo derivado do verbo ilon (nomear). $\mathrm{N}$-: prefixo possessivo indicando o indefinido; -lon-: raiz do verbo nomear; -axat: sufixo nominativo do verbo.

${ }^{9}$ A situação descrita por vários etnógrafos, no início do século XX, sobre o emprego dos nomes toba e seu modo de transmissão transformou-se acentuadamente ao longo dos últimos cinqüenta anos. Com relação aos nomes próprios, aos nomes dos bandos (tropillas) e aos apelidos, o que se verificou foi a utilização cada vez mais freqüente do espanhol. Paralelamente, este uso foi interrompido por um fato histórico capital para as populações indígenas da Argentina: a atribuição da carteira de identidade durante o governo do General Juan D. Perón. Nos anos 50, mesmo que os Qom tenham adquirido pela primeira vez sua carteira de identidade, eles foram inscritos arbitrariamente com nome e sobrenome espanhol na prefeitura das Províncias do Chaco. Uma análise desse processo histórico de deslocamento dos nomes e dos sobrenomes da língua toba para o espanhol impõe-se. Os nomes próprios e os dos grupos dos antigos Qom faziam geralmente referência às características físicas dos indivíduos e do grupo, o que se assimilava à lógica da utilização dos topônimos a partir das características topográficas. Nos nomes de territórios, naqueles dos bandos e dos indivíduos, permaneceram marcas da conquista do Chaco. Encontram-se nomes próprios como Salataxanashe ( $\mathrm{s} a$-: forma de negação; -lataxana: verbo submeter, perseguir; -she: forma feminina), que evocam aquela que não foi submetida ou aquela que sobreviveu à guerra (quando os antigos falam da guerra, eles fazem referência notadamente à conquista do Chaco, iniciada em 1884). Há também topônimos como so rocshec ilo (o Branco olhou (so: partícula dêitica que indica algo em movimento, o passado; rocshec: nome singular designando um Branco; ilo: terceira pessoa do verbo olhar), além de nomes de grupos, como eraxai (verme luzente).

${ }^{10}$ Pi'oxon-aq: -pi'oxon-: raiz do verbo sugar; -aq: sufixo que indica aquele que é perito. Cona-xananae (-cona: raiz do verbo tomar; -xanaxae: aquela que realiza a ação do verbo). Este termo é fundado na ação da feiticeira que pratica a feitiçaria por contágio: ela pega um objeto pertencente à vítima. Sobre xamanismo e feitiçaria, cf. Karsten (1932), Métraux (1967), Cordeu (1969-70), Miller (1979) e Palavecino (1935).

${ }^{11} \mathrm{Na}$ época pré-colombiana, a maioria das sociedades indígenas do Chaco praticava uma economia nômade ou seminômade fundada na caça, na pesca e na colheita. Vários autores consideraram o bando como a unidade primeira da organi- 
zação social no Chaco (Karsten 1932; Métraux 1963; Cordeu e De Los Rios 1982; Braunstein 1983). O bando era considerado "um grupo local de famílias extensas constituído particularmente sobre as bases do parentesco e da afinidade" (Braunstein e Miller 1999:10). Por outro lado, a tribo representava um conjunto regional de bandos. Segundo alguns autores, as tribos eram "a extensão maior dos limites dos elos de parentesco" (Braunstein 1983:31). Cada uma delas era geralmente identificada por um nome comum. Elas efetuavam também trocas e, entre os bandos que as formavam, contraíam-se alianças de casamento (Braunstein 1983; Braunstein e Miller 1999). Os bandos aliados encontravam-se esporadicamente para celebrar a festa da alfarrobeira. Atualmente, é difícil observar a composição dos bandos, assim como o pertencimento dos indivíduos toba a uma tribo, em razão das mudanças de modelos de residência e de regimes matrimoniais nas comunidades rurais e urbanas. A localização atual dos Toba é em parte uma conseqüência da pressão exercida pelo avanço do exército nacional, em torno dos finais do século XIX, nos territórios do Chaco argentino. Os Qom vivem atualmente em comunidades permanentes - rurais, periurbanas e urbanas - onde eles coabitam com os membros de antigos bandos e tribos.

${ }^{12} N^{\prime}$ na-axat. N'an-: raiz de um substantivo derivado do verbo i'an (fazer uma marca); axat: sufixo permitindo substantivar um verbo (marca, sinal).

\section{Referências bibliográficas}

BECKERMAN, Stephan \& VALENTINE, Paul. 2002. Cultures of multiple fathers. The theory and practice of partible paternity in Lowland South America. Gainesville: University Press of Florida.

BÓRMIDA, Marcelo. 1969. "Mito y cultura". Runa, 7:9-52. 1976. Etnología y fenomenología. Buenos Aires: Cervantes.

BRAUNSTEIN, José. 1983b. “La passion amoureuse chez les Mataco". Journal de la Société des Américanistes, LXIX:169-176.

BRAUNSTEIN, José \& MILLER, Elmer (orgs.). 1999. Peoples of the Gran Chaco. Westport: Bergin and Garvey. CALIFANO, Mario. 1973. "El ciclo de Tokjwaj: análisis fenomenológico de una narración mñitica de los Mataco costaneros". Scripta Etnologica, 1(1):157-186.

CORDEU, Edgardo. 1969-70. "Aproximación al horizonte mítico de los Tobas". Runa, 12(1-2):67-176.

. \& DE LOS RIOS, Miguel. 1982.

"Un enfoque estructural de las variaciones socioculturales de los cazadores-recolectores del Gran Chaco". Suplemento Antropológico, 17(1):131-195.

DASSO, Cristina. 1988. "Las transformaciones del sol y las estrellas en la cosmovisión de los mataco (grupo tachonai)". Scripta Ethnologica, 9:29-42.

DE LOS RÍOS, Miguel. 1976. Una visión shamánica del ciclo vital (etnia mataco). Buenos Aires: Tekné. 
1978-79. "La expresión de la pasión amorosa en la etnia mataco". Scripta Ethnologica, 5(1):26-51.

DESCOLA, Philippe. 1992. "Societies of nature and the nature of society". In: Conceptualizing society. Londres: Routledge. pp. 107-126.

. 1996. "Constructing natures: symbolic ecology and social practice". In: Nature and society, anthropological perspectives. Londres: Routledge. pp. 82-102.

2000-2001. Anthropologie de la nature. Résumé des cours et travaux. Paris: Anuario del Collège de France.

DUCCI, Fray Zacarias. 1904. Los Tobas de Tacaagalé, Misión San Francisco Solano. Arte y vocabulario toba-castellano y un mapa. Buenos Aires: Imprenta La Buenos Aires.

GORDILLO, Gastón. 1996. "Hermenéutica de la ilusión: la etnología fenomenológica de Marcelo Bórmida y su construcción de los indígenas del Gran Chaco". Cuadernos de Antropología Social, 9:135-171.

HÉRITIER, Françoise. 1994. Les deux sœurs et leur mère. Anthropologie de l'inceste. Paris: Éditions Odile Jacob.

1996. Masculin / Féminin. La pensée de la différence. Paris: Éditions Odile Jacob.

HUGH-JONES, C. 1979. From the milk river. Spatial and temporal processes in Northwest Amazonia. Cambridge: Cambridge University Press.

IDOYAGA MOLINA, Anatilde. 1976.

"Matrimonio y pasión amorosa entre los mataco". Scripta Ethnologica, $4(1): 46-67$.

. 1978-79. "Contribución al estudio del proceso de gestación, aborto y alumbramiento entre los mataco costaneros". Scripta Ethnologica, 5(2):143-155.
IÑIGO CARRERA, Nicolás. 1979. La violencia como potencia económica: Chaco 1879-1940. Buenos Aires: Centro Editor de América Latina. 1983. La colonización del Chaco. Buenos Aires: Centro Editor de América Latina.

KARSTEN, Raphael. 1926. The civilization of the South American indians. Londres: Kegan Paul, Trench, Trubner and CO.

. 1932. "Indian tribes of the argentine and bolivian Chaco. Ethnological studies". Societas Scientiarum Fennica, 4(1):10-236.

KERSTEN, L. 1968. Las tribus indígenas del Gran Chaco hasta fines del siglo XVIII. Resistencia: Universidad del Nordeste, Facultad de Humanidades.

MASHNSHNEK, C. 1976. "El mito en la presencia de los aborígenes del Chaco Central: presencia y actuación de las teofanías". Scripta Ethnologica, 4(1):6-27.

MENDOZA, Marcela. 1999. "The Western Toba: family life and subsistence of a former hunter-gatherer society". In: J. Braunstein \& E. Miller (orgs.), Peoples of the Gran Chaco. Westport: Bergin and Garvey. pp. 81-108.

MÉTRAUX, Alfred. 1937. "Études d'ethnographie Toba-Pilagá (Grand Chaco)". Anthropos, Revue Internationale d'Ethnologie et de Linguistique, 32:171-194 e 378-401.

. 1946. Myth of the Toba and Pilagá indians of the Gran Chaco. Philadelphia: American Folklore Society.

. 1963. "Ethnography of the Chaco". In: Handbook of South American indians 1. New York: Cooper Square Publishers, INC. pp. 01-306. 1967. Religions et magies indiennes d'Amérique du Sud. Paris: Gallimard. 
MILLER, Elmer. 1979. Los tobas argentinos. Armonía y disonancia en una sociedad. Mexique: Siglo XXI.

NORDENSKIÖLD, Erland. 1912. "La vie des indiens dans le Chaco: Amérique du Sud". Revue de Géographie, 6(3):1-278.

PALAVECINO, Enrique. 1935. "Nota sobre la religión de los indios del Chaco". Revista Geográfica Americana, 2(21):373-380.

SEEGER, Anthony, DAMATTA, Roberto \& VIVEIROS DE CASTRO, Eduardo. 1979. "A construção da pessoa nas sociedades indígenas brasileiras". Boletim do Museu Nacional, 32:2-19.

STRATHERN, Marylin. 1988. The gender of the gift. Berkeley: University of California Press.

TAYLOR, Anne-Christine. 1993. "Remembering to forget: identity, mourning and memory among the Jivaro". Man, 28(4):653-678.

. 1998. "Corps immortels, devoirs d'oubli: formes humaines et trajectoires de vie chez les Achuars". In: M. Godelier \& M. Panoff (orgs.), La production du corps. Amsterdam: Éditions des Archives Contemporaines. pp. 317-338.

TOMASINI, Alfredo. 1978-79. "La narrativa animalística entre los tobas de Occidente". Scripta Ethnologica, 5(1):52-81 .

TOLA, Florencia. 2004. "Je ne suis pas seul(ment) dans mon corps". Corps et multiplicités chez les Toba (Qom) du Chaco argentin. Thèse de Doctorat, Paris, Ecole des Hautes Etudes en Sciences Sociales - Université de Buenos Aires.

TRINCHERO, Hugo. 1994. "Entre el estigma y la identidad. Criollos e indios en el Chaco salteño". In: Cultura e identidad en el Noroeste argentino. Buenos Aires: Centro Editor de América Latina. pp. 96-119.

. \& LEGUIZAMÓN, Juan Martín. 1995. "Fronteras de la modernización. Reproducción del capital y de la fuerza de trabajo en el umbral al Chaco argentino". In: Producción doméstica y capital. Buenos Aires: Biblos. pp.15-44. . 1996. "La estructura del estigma: porqué los indios llegaron a comer pescado crudo". Papeles de Trabajo, 5:79-89.

TRINCHERO, Hugo; PICCININI, D. \& GORDILLO, Gastón. 1992. Capitalismo y grupos indígenas en el Chaco Centro-Occidental (Salta y Formosa)/1. Buenos Aires: Centro Editor de América Latina.

VIVEIROS DE CASTRO, Eduardo. 1992. From the enemy's point of view. Humanity and divinity in an amazonian society. Chicago: University of Chicago Press.

. 1996. "Os pronomes cosmológicos e o perspectivismo ameríndio". Mana. Estudos de Antropologia Social, 2(2):115-144.

. 2002. A inconstância da alma selvagem. São Paulo: Cosac \& Naify.

VILAÇA, Aparecida. 1992. Comendo como gente: formas do canibalismo wari (Pakaa Nova). Rio de Janeiro: Anpocs / Editora da UFRJ.

2005. "Chronically instable bodies: reflections on amazonian corporalities". Journal of the Royal Anthropological Institute, 11:445464.

WRIGHT, Pablo. 1997. Being-in-the-dream. Postcolonial explorations in toba ontology. Thèse de Doctorat, Temple University. 


\section{Resumo}

Neste artigo, analiso os atributos que definem a pessoa e o corpo entre os Toba (Qom) do Chaco argentino. O interesse pelo conceito de pessoa e de corpo levoume a abordar alguns componentes deste último, como os fluidos corporais, o lqui'i (traduzido habitualmente por alma), alguns nomes e o calor. Finalmente, reflito sobre os mecanismos de individuação que operam mesmo quando a pessoa é concebida como feixe no qual se entrecruzam relações.

Palavras-chave: Corpo, Pessoa, Individuação, Agência, Grande Chaco
In this article, I analyze the attributes that define person and body among the Toba (Qom) of the Argentine Chaco. An interest in these concepts led to an examination of some of the components of the body such as corporal fluids, the lqui'i (usually translated as soul), various names and body heat. Finally, I discuss the mechanisms of individuation that operate event when the person is conceived as a bundle where relations intersect.

Key words: Body, Person, Individuation, Agency, Grande Chaco 